\title{
Psychiatric disturbance in chronic renal failure and its treatment by dialysis
}

\author{
J. Donovan Hailstone \\ B.SC., M.B., B.S., D.P.M. \\ Physician in Psychological Medicine, Royal Free Hospital, London, W.C.1, \\ Consultant Psychiatrist, Friern Hospital and Halliwick Hospital, London
}

\begin{abstract}
Summary
The psychiatric disturbance in patients with chronic renal failure is described and some of the aetiological factors reviewed.

A number of psychiatric problems arise during the course of treatment by haemodialysis, both among patients, relations and members of dialysis teams. Their course, treatment and prognosis are discussed.
\end{abstract}

SinCE Alwall (1960) and Scribner and his colleagues (1960) first described the treatment of terminal renal failure by long term dialysis there has been an increasing volume of literature on the psychological pitfalls of this procedure. Psychiatrists and psychologists have been fascinated by the particular problems apparently posed by the newly formed renal units and there has been considerable speculation about the impact of 'survival by machine', an impact felt not only by the patient but also by his family and by his medical attendants. Much of the literature has inevitably been psychodynamic in emphasis, for example, a paper by Kaplan De-Nour (1969) who speculates that the loss of urination experienced by patients undergoing chronic haemodialysis may cause regression to pre-genital stages of development, affect body image, sexual identity and the handling of aggressive impulses.

It is important that the psychiatrist, when asked for an opinion by his renal unit colleagues, should be able to strike a proper balance between the psychodynamic and the biochemical. It is hoped that this review will be of some guidance.

The psychological manifestations of renal failure were described by Addison in 1868 in his classic monograph on kidney disease. He wrote that these patients manifested 'a dullness of the intellect, sluggishness of manner, drowsiness going on to quiet stupor and ending in coma'. Schreiner (1959) and Tyler (1965) agree that the commonest initial complaints of the uremic patient are fatigue, drowsiness and the inability to concentrate for long periods. The concentration difficulty is always episodic; the patient can perform accurately and well in short spurts but cannot sustain activity. This impaired functioning is an early and sensitive index of brain dysfunction appearing prior to neurological symptoms. As the disease progresses, the apathy which is associated with it will extend to visceral spheres: the patient becomes choosy of appetite, sexual desire and performance begin to wane, severe anorexia may hasten weight loss and in general the patients are emotionaly dull and unengaged. Whilst complaining of drowsiness by day uremic patients frequently have insomnia at night. They may show depressed, demanding, discontented and paranoid behaviour which add to the difficulties in their management by hospital staff. They often soil and wet the bed although they have voluntary control of excretory functions.

Schreiner (1959) comments that delirious psychoses may arise even in the early stages of the alteration of consciousness but increase in frequency occurs along with the deterioration of the general mental state. These delirious states however are not inevitable psychic disturbances; fatigue, apathy, depression, irritability and amnestic symptoms may merge into stupor and eventually into coma which, prior to treatment by dialysis, almost always terminated fatally. Faulty orientation, delusions and hallucinations are present to a varying extent.

Kemph (1966) suggests that the neuro-psychiatric changes are probably concomitant with chemical changes. All the twelve patients whom he studied did develop psychotic behaviour although they presented with the agreed composite picture of personality change, fatigue, apathy, drowsiness followed by anorexia and disturbances in thinking and depressive signs. The depressive trends, he suggests, were based on an awareness of impending death.

Stenbäch \& Haapanen (1967) found psychiatric disturbances in fifty-three out of their ninety cases; thirty-three of these were diagnosed as delirious. a term employed by the authors to describe cases where clouding of consciousness, disorientation, delusions and hallucinations were pre-eminent features of the mental state. The frequency of all psychiatric disturbance was higher in the patients with a serum urea concentration of $250 \mathrm{mg} / 100 \mathrm{ml}$. The same was true of the presence of delirium and a significantly 
higher frequency of delirium was found in patients who died during the study period. The authors did not find any indication of a preponderance of psychiatric disturbance in the acute patients over the chronic patients.

The aetiology of the psychiatric disturbance in renal failure

\section{Biochemical disturbances}

The cause of the psychiatric disorders in renal failure is still not well understood and the clinical condition probably results from a multiplicity of biochemical disturbances. Many authors are agreed that there is frequently a striking lack of correlation between the symptoms and the degree of renal impairment (Merrill, 1965). Merrill suggests that the amount of symptomatic difficulty shown by the patient in renal failure is perhaps more a question of the rate of progress of the underlying disease than anything else. The tolerance of and compensation for severe chemical abnormalities induced by chronic renal failure can be remarkable and when the disease progresses slowly, mild fatiguability may be the only complaint of patients with marked nitrogen retention and anaemia.

Moderate losses of sodium chloride in excess of intake may result in nothing but fatigue and occasional 'salt cramps' manifested particularly in the calves (Merrill, 1965). A negative potassium balance may be manifested by weakness, disorientation and diminution of reflexes but these symptoms may also be typical of hyperpotassemia. Serium calcium is frequently depressed although it may be normal or occasionally raised if there is secondary hyperparathyroidism and the raised serum magnesium, which is usual in chronic renal failure, may contribute to the drowsiness and depressed reflexes.

There is scant literature on the role of electrolyte imbalance in the aetiology of psychiatric illness generally, although the biochemistry of the affective disorders has been carefully reviewed by Coppen (1967). Most of the published work has been directed towards finding electrolyte abnormalities in patients suffering from or recovering from depressive and hypomanic illnesses but as Coppen says, in the present state of our knowledge, it is not possible fully to evaluate the importance of the changes in electrolyte distribution in affective disorders. There is however some work which suggests that changes in water and electrolyte distribution may alter mental state. He quotes the work of Bussow who gave water and vasopressin to patients suffering from mania and depression and found that both the manic and the depressive features became very much worse. The same procedure was repeated on six normal subjects producing symptoms of a depressive illness.
Anaemia in renal failure undoubtedly contributesڤ to the patients' complaints of fatiguability, although their subjective feelings are characteristically not related to their haemoglobin levels until profound $ᄃ$.

degrees of anaemia are reached.
Similarly blood urea and nitrogen levels are not reliable either as a sole guide to control of the uremice syndrome or to the expected subjective feelings of the patient, although high concentrations of ureaundoubtedly impair the function of enzyme systems.

There has been an exhaustive search for ones 'toxin' to explain the signs and symptoms of uremia $\vec{\circ}$ but as yet no such substance has been found. It hasbeen suggested however by Kemph (1966) that therew must be a considerable contribution to the clinicato state from a molecular metabolite of a size which would be filtered by the kidney but not by membranes used in haemodialysis, i.e. a particle of a size less than $30 \AA$ units.

The excretion of catecholamines is impaired including probably the excretion of norepinephrine and epinephrine. Merrill (1965) suggests that this fact mayo account for the occasional uremic patient who presents with striking increase in pulse pressure, $\vec{D}$ severe headache and high output failure, all of which are improved by the administration of phentolamiones giving a 'false positive phentolamine test'. It is important to bear this in mind in the choice of ans depressants if these are to be used at all in tedepressed uremic patient. The mono-amine oxidase? inhibitors are best avoided.

\section{Treatment regimens}

Traditionally the dietary regimen in chronic renal $\overrightarrow{\vec{A}}$ failure includes a restriction of protein but Merrill 3 (1965) believes that the need for restriction has? probably been overstressed and that the extreme? weakness and lethargy seen in some uremic patientso on drastically reduced protein diets may be due to 3 . this therapeutic approach pioneered by Addis (1949). Certainly in the author's experience the patient with this type of severe protein restriction finds the dietô extremely irksome and a constant reminder of his illness even though he may be in other respects? symptom free. Patients comment that the diet is $>$ 'depressing' and 'monotonous' and the restrictions? may contribute both physiologically and psychologically to the patient's depression. The Giovanetti ${ }^{\text {Fr }}$ diet though supplying essential amino acids is found 0 particularly unpleasant by many patients.

Patients with chronic renal failure frequently으 suffer from hypertension which is refractory to anti-o hypertensive agents and in any case if the blood pressure is lowered this may decrease the filtration $\stackrel{\mathscr{P}}{+}^{+}$ rate and increase the azotemia. Anti-hypertensive ${ }^{\circ}$ drugs are notorious for their production of $\frac{}{\vec{P}}$ 
psychological side-effects, particularly for producing depressive reactions.

Reserpine has been known for some years to produce quite severe reactions of this sort. Alpha methyldopa is commonly used and again the depressive reactions of this drug are well documented. The substance inhibits the enzymatic decarboxylation of dopa in vitro and in vivo and would thus interfere with the formation of dopamine from dopa. It is conceivable, argues Smirk (1963), that there would be a decrease in the synthesis of noradrenaline. The enzyme also inhibits the decarboxylation of 5hydroxytryptamine. It thus interferes with the synthesis of noradrenaline and serotonin in the brain and other tissues; its action in some respects resembles that of reserpine.

Mielczarek (1962) described the case of a middleaged woman who became depressed, tense and agitated after administration of the drug for 5 days. Despite that fact that the tablets were discontinued she remained depressed and 10 weeks later was severely depressed with ideas of guilt and suicidal thoughts. These symptoms improved with a course of ECT. Smirke (1963) reported five cases who showed depressive symptoms out of fifty-three patients treated with the drug. All improved when methyldopa was stopped. He described other manifestations such as peculiar feelings of detachment, emotional disturbance and alteration of sleep rhythm with insomnia as well as drowsiness.

The adrenergic blocking agent bethanidine is also reputed to produce depressive side-effects and it is recommended by the manufacturers that it should not be used in patients with a history of depression. The manufacturers can produce no direct evidence that the drug induces depressive complications directly but suggest that the very fact of reducing blood pressure may induce a depressed outlook onlife.

The use of the corticosteroids introduces more possibilities for psychiatric disturbance although there is surprisingly little literature concerned with the mental complications encountered when using these powerful drugs. One of the earliest observations made by a psychiatrist was by Fleminger (1955) who found the use of ACTH produced more depression as a side-effect whereas cortisone produced more elation and euphoria. The more common minor central nervous system manifestations accompanying steroid therapy are insomnia, restlessness, aggressiveness, irritability, cyclic change of mood and marked increase in appetite. When such manifestations occur they are not necessarily persistent nor do they herald the development of a later more severe psychiatric disturbance.

The incidence of disturbance following treatment with corticosteroids seems to be greater in the young. Bondarev (1963) reports neuropsychiatric distur- bances in thirty-four of his series of eighty-seven children treated with corticosteroid therapy. Twentyone of them showed a rapidly transient euphoria, nine a slight depression, one a marked depressed reaction and three an acute psychotic state with fear, anxiety and optical illusions and distortions of body image. All affected patients responded with appropriate treatment with tranquillizers and withdrawal of the drug and all states were found to be reversible. Ishikawa et al. (1964) have described two cases of psychotic reactions in adolescents on prednisolone/ prednisone, dexamethasone and betamethosone. Both of their patients, a girl of 11 and a boy of 15 had chronic nephrosis and developed acute psychoses which resolved spontaneously and abruptly on withdrawal of the drug. They estimate the incidence of psychiatric disturbance on corticosteroids in their clinic of $1.1 \%$ and according to other Japanese authors the incidence varies from $0.3 \%$ to $9 \%$. There is no consistent correlation with dosage, onset, duration of psychosis, pre-morbid personality or laboratory findings.

With the more frequent use of corticosteroids in clinical medicine steroid psychoses are becoming more prevalent and although these disturbances usually run a benign course with a good prognosis they certainly interfere with the usefulness of the drugs and often restrict their clinical use.

\section{Secondary involvement of other systems}

Cardiac and pulmonary involvement may complicate the presenting clinical picture. Anaemia, hypertension, coronary artery disesase and sodium retention all contribute to the cardiac failure seen in chronic uremia and the metabolic abnormalities of uremia also play a part in the disturbance of cardiac function and the development of pulmonary oedema. The combined effect of these cardiac and pulmonary complications of the disease may produce symptoms of cerebral hypoxia, presenting as a toxic confusional state with restlessness, dysmnesia, clouding of consciousness and loosely woven paranoid ideas.

The gastro-intestinal system is frequently affected, anorexia and nausea being the commonest symptoms of renal failure with hiccoughing a frequent and annoying accompaniment. These symptoms inevitably increase the patient's awareness of his plight and contribute to the psychic stresses to which he is subject.

The central nervous system too is inevitably involved and as Merrill (1965) points out there are striking similarities between the neurological signs and symptoms of uremia and those of hepatic failure although the chemical derangements are quite dissimilar. False localizing signs may appear in both conditions and these may include nystagmus, transient facial asymmetry, dysarthria and hemi- 
anopia. Visual acuity may be impaired and this may resemble a toxic amblyopia.

Patients with advanced uremia may show asterixis, muscular twitching, hyper-reflexia, tetany and convulsions. There are symptoms resembling a peripheral neuritis; some patients complain particularly of severe pain over the dorsum of the foot, instep or heel.

Convulsions too frequently occur although their precise aetiology is still obscure. Focal convulsions usually signify focal brain damage, localized bleeding or widespread arteritis. In one study of 110 patients who had convulsions during the course of their renal failure, Tyler (1965) found the coexistence of hypertension and disturbed electrolyte imbalance was most likely to lead to convulsions; other factors particularly provocative were rapid changes in $\mathrm{pH}$ usually caused by aggressive treatment with bicarbonate solution, rapid drop in blood urea nitrogen levels associated with haemodialysis, peritoneal dialysis or sudden diuresis, and excessive shifts of water. Tyler was unable to correlate seizures specifically with any particular electrolyte abnormality. Fifty per cent of his series had other serious disturbances of their state of consciousness, $10 \%$ had evidence of a peripheral neuritis and in $40 \%$ asterixis or marked fasciculations were noticed often with myoclonic phenomena.

The electroencephalogram may be markedly but non-specifically abnormal. Excessively slow frequencies are described and Tyler (1965) confirms that the most common abnormality takes the form of diffuse slowing with a tendency for paroxysmal bursts of slow waves arising bilaterally from the frontoparietal and para-sagittal areas. There was no correlation between the clinical state and the electroencephalogram and the abnormalities reported were frequently seen in patients without seizures. Again Tyler was unable to correlate the EEG abnormalities with any blood chemical determination, i.e. sodium, potassium, chloride, calcium, phosphate or $\mathrm{CO}_{2}$ content although it was thought that the EEG often became 'worse' if there was a rapid shift in electrolytes.

The relationship between symptoms, disease process and prognosis in chronic renal failure

One of the most striking features of renal failure is the apparent lack of correlation between organic disturbance and the patient's subjective disability. Merrill warns of the dangers of treating patients with chronic renal failure with a sense of therapeutic and prognostic futility and he says that such an approach is bound to communicate itself to the patient. Although prognosis in chronic renal failure is generally grave, he says, an occasional patient tolerates nitrogen retention for many years even in the presence of elevated blood pressure. He warn§ against the physician communicating his ow anxieties to the patient and says that therapeutie optimism communicates itself to the patient aseffective psychotherapy often resulting in the relies of many of the non-specific symptoms of chronic renal failure. 'We do them an ill service if we force्s them to participate in our fears or even in our cer⿳亠口冋. tainties. They do not listen to us, they wait fo deeper intimations of their mortality. That voice्d they will hear because it is their own and that message they will receive with no resentment or dismays (Addis, 1949).

\section{The treatment of renal failure by dialysis}

The mental, emotional and personality distur bances encountered by patients undergoing dialysis. may be due to a number of causes; to uraemia, to provocation of the chronic debilitatıng disease or tof the effects caused by the repeated technical pros cedures of the dialysis.

Some of the more immediate psychological effects are undoubtedly caused by biochemical changes. Kennedy et al. (1962) describes symptoms of worsen $\Rightarrow$ ing mental confusion, headaches or the developmen of confusion during haemodialysis. He attributes 禹通 exacerbation of symptoms to the slower passagenof urea from the brain than from the blood, thus cams ing an osmotic pressure gradient between the brain and the blood. Water is drawn back into the and this causes an increase in CSF pressure. In later paper (Kennedy et al., 1963) he describes EEG changes in patients undergoing dialysis which hஜे says are similar to the non-specific changes seen i⿱ patients known to have increased intracranial pres $\overrightarrow{\bar{O}}$ sure. These changes were considerably reduced by adding more glucose to the dialysing fluid, by per? forming the dialysis without urea removal, and to lesser extent by intravenous infusion of concentrate fructose solution.

Maher, Freeman \& Schreiner (1965) describe theip experiences with seven patients who survived an average of 8 months under haemodialysis. In the group the blood urea nitrogen levels were reduced by an average of $41 \%$ of pre-dialysis levels but the blood urea nitrogen levels were not reliable as a sole guide to the control of the uraemic syndrome. Ale. their patients remained alert and their severe biof chemical abnormalities were controlled. However they still showed bone demineralization, hyperten sion, variable abnormalities of hydration, potassiunw depletion, hyperkalemia, anaemia, haemosiderosig and increased incidence of drug toxicity, peripheraf neuropathy and psychiatric disturbances. Despit this the authors conclude that the stress of dialysis seemed minimal but then described one patient who developed a paranoid psychosis and another who्ष 
bled to death from his Teflon cannula. It was thought that this 'accident' may have been self-induced although those with experience in renal units will undoubtedly recall similar incidents where the suicidal intent was clear. Another case of acute psychosis during haemodialysis is described by Cooper (1967). Here the patient developed acute hypomania, precipitated it was thought by accumulated psychological traumata and triggered by haemodialysis. Cooper considered the psychosis a predominantly functional illness rather than one due to metabolic abnormalities. The decompensation was treated successfully with chlorpromazine and psychotherapy.

As the literature on the maintenance of patients with chronic renal failure by recurrent peritoneal or haemodialysis accumulates so have authors paid more attention to the psychological difficulties encountered. One of the earliest workers to describe his experiences, Scribner (1960), observed that his patients became easily fatigued and seemed to lack stamina. Gombos et al. (1964) were among the first to study these patients in depth. They gave their patients the WAIS, MMPI, Rorschach and the Stein completion test. They found that the patients' pre-dialysis anxiety level, his degree of dependency and the absence of intrusive psychological conflicts were important in assessing his ability to benefit from an intermittent dialysis programme. In 1965 Shay et al. published their observations on nine intermittent haemodialysis patients seen over the past $2 \frac{1}{2}$ years. All showed psychological reactions to dialysis. The night before they were due to be dialysed they were restless, irritable and apprehensive. This apprehension was seen even in the experienced patients and was often associated with insomnia. During dialysis the main reaction was one of boredom and lethargy although there were moments of maximum anxiety when at the beginning and the end of the procedure the shunt was connected and disconnected. The patients' tolerance of the procedure diminished as their experience of it increased. After dialysis there were temporarily listless and Shay ascribes this to the loss of water and temporary dehydration. They conclude that acceptance of and adjustment to the basic disease process was generally poor and the additional stress of dialysis produced schizophrenia-like episodes in two of their patients, a psychotic depression in one and a number of severe neurotic depressive reactions in all but one of the others. The dietary indiscretions were particularly seen as manifestations of stress, an observation made too by Cramond (1967) who comments on the importance of the diet as a means of displacing anger and hostility; by refusing meals patients can worry staff and again use the food and eating situation aggressively.
Much of the psychological stress encountered in patients undergoing intermittent dialysis can be thought of in terms of losses or threats of losses, or as frustration of drives. In varying degrees patients experience loss of parts of the body or body function, loss of membership of groups, failure of longterm plans or ambitions, change in way of life or living, loss of home, possessions or financial status and loss of job or occupation. Wright, Sand \& Livingstone (1966) have outlined the defensive reactions encountered in these patients. The main ones seen were denial ('living with my illness', 'awaiting perfection of transplantation') and projection ('other patients worse off than me'). Many authors have stressed the importance of denial in the chronic haemodialysis patient and many believe it to be a useful if not an essential protective mechanism in an otherwise intolerable situation.

In the review by Cramond et al. (1967) of twentyone cases the authors comment on the massive denial seen as patients try to deal with the initiation into dialysis-the patients need to deny such unwelcome news as, for example, that the kidneys will never function again or that dialysis will have to be recurrent in order to maintain life. Three patients regressed, showing either childish sulky withdrawal or difficult, demanding and dramatic behaviour. Another patient became floridly psychotic with paranoid delusions. As time goes on and patients cease to deny their illness they realize they have lost their health and independence and that their future and financial position are uncertain. Cramond's patients then showed the mourning reaction already described and seen in other patients ill with chronic disease. The grief reaction may be within normal limits and amenable to supportive psychotherapy or, where clinical depression exists, to treatment with amitryptyline and/or diazepam. From time to time all their patients wished to be dead although none was actively suicidal. Five passed from the mourning reaction into a state of active depression and another was found dead at home apparently from natural causes although there was no obvious pathological reason why he should have died. One patient became terminally profoundly depressed and agitated and was treated by ECT on two occasions without effect. In the present author's opinion the risk of suicide in these patients should not be underestimated; a recent questionnaire study with data on 3478 dialysis patients revealed that 166 of them had ended their lives through active or passive suicidal behaviour (Abram, 1970).

Psychological problems of the staff of the dialysis unit

It is not surprising that in intermittent dialysis units there is a great deal of emotional investment of all staff in their charges. Because of the nature of the 
treatment, its longevity and its life-prolonging nature staff members have a great deal of emotional involvement in the situation. Cramond et al. (1967) point out that staff members develop a countertransference to the patient, and team members coming as they do from a variety of disciplines, surgical, medical, nursing, technical, have all to learn something of their own tensions, to tolerate their inability to be omnipotent, to understand and make allowances for the loss of love objects, namely the patients. The intense emotional support which needs to be given to patients and their families over months and years is rewarding when things go well but difficult to tolerate when they go wrong and patients are reproachful or hostile, acting out and 'unco-operative'.

De-Nour \& Czaczes (1968) have made a special study of the emotional problems and reactions of the medical team in a chronic haemodialysis unit. They found that the team's aggression is a major unsolved problem and that the team demands that the patient should do extremely well on treatment and tends to deny that patients are ill. The physicians in the unit tended to defend themselves by withdrawing from the patients as well as by denying the extent of the patients' disability. Nurses on the other hand showed a compensatory over-protectiveness and possessiveness towards the patients and these two attitudes were found to produce progressively deteriorating inter-staff relationships if not dealt with. Shea et al. (1965) were impressed by the moodiness, irritability, intense dependency and insatiable demands often shown by haemodialysis patients. These demands often tax the staff and much depends upon staff attitudes. Patients often wish to be allowed to die and if the staff themselves see dialysis as a frustrating unrewarding prelude to death then the morale of the whole unit will suffer. Cramond (1967) makes a case for specialist help in dealing with these emotional problems on a dialysis unit.

\section{Emotional problems of patients' relatives}

The stresses encountered by patients undertaking an intermittent dialysis programme have been described by Wright et al. (1966) but it must be remembered that these stresses will be reflected in the family of the patient and a great deal of compensation is required on behalf of the other members to accommodate the now chronically ill member who may originally have been the main financial and emotional support. Gombos (1964) has stressed the importance of strong emotional support from other family members in the management of the chronic dialysis patient and both Cramond (1967) and Macnamara (1967) have given accounts of their own experiences with the families of these patients and have particularly stressed that pre-selection for the programme should take particular account of ân accurate assessment of the family situation. This hat become much more important as techniques fô home dialysis have been perfected. Shambaugh et at (1965) report a psychological study of eighteen spouses of patients on haemodialysis in the homet The spouses were affected by multiple losses and frustrations especially the patient's psychological regression and possible death. They responded wit feelings of deprivation and hostility. Whilst operato ing the artificial kidney they had to cope with their own murderous fantasies. Some spouses develope $\$$ regressive reactions, especially severe depression $\overrightarrow{\vec{H}}$ excessive closeness, denial and avoidance. Spouse who became especially close to their sick partne would never leave them alone and became patho logically over-protective of them. It is now realized that home dialysis will only properly succeed if the patient can come to depend upon himg self for the necessary technical operations involvedr

The psychiatric disturbances encountered i chronic renal failure and in dialysis, may then be 9 product of a variety of factors, both organic and functional. If psychiatric referral is to be profitable then a similar versatility is to be expected from the psychiatrist himself. Physical methods of treatment? individual, group and family therapy may be ingli $\overline{0}$ cated, and the needs of patient, family and stafiat given their proper due.

\section{References}

Abram (1970) Survival by machine: the psychological stre of chronic haemodialysis. Psychiatric Medicine, 1, 37

ADDIs, T. (1949) Glomerular Nephritis: Diagnosis and Trea? ment. Macmillan, New York.

AdDison, T. (1868) A Selection of the Collected Works as Thomas Addison (Ed. by Wilks \& Daldy). New Sydenham Society, London.

Alwall, N. (1960) Proceedings of the First Internationat Conference of Nephrology. Karger, Basle.

BoNDAREV, V.N. (1963) Neuropsychiatric disturbances iñ. children following corticosteroid therapy. Zhurnal nevro patologii $i$ psikhiatrii imeni S.S. Korsakova, 63, 1094.

COOPER, H.J. (1967) Hypomanic psychosis precipitated bis haemodialysis. Comprehensive Psychiatry, 8, 168.

COPPEN, A. (1967) Biochemistry of affective disorders. British Journal of Psychiatric Social Work, 113, 504. 은

CRAMOND, W.A., KNIGHT, P.R. \& LAWRENCE, J.R. (1967) The psychiatric contribution to a renal unit undertaking chronic haemodialysis and renal transplantation. Britisł Journal of Psychiatric Social Work, 113, 1201.

De-Nour, A.K. \& CzACzes, J.W. (1968) Emotional problems and reactions of the medical team in a haemodialys unit. Lancet, ii, 987.

Fleminger, J.J. (1955) Differential effects of ACTH and cortisone on mood. Journal of Mental Science, 101, 12s.

Gombos, E.A., LeE, T.H., HaRton, M.R. \& Cummings, J. (1964) Haemodialysis for CRF: IV. Psychological con
siderations. Annals of Internal Medicine, 62, 558.

IshiKara, S., MotoKI, K. \& KoKaWA, I. (1964) Mentat disorders associated with corticosteroid therapy. Shikok $\overline{\bar{O}}$ acta medica, 20, 369. 
KaPlan De-Nour, A. (1969) Some notes on the psychological significance of urination. Journal of Nervous and Mental Disease, 148, 615.

KEMPH, J.P. (1966) Renal failure, artificial kidney and kidney transplant. American Journal of Psychiatry, 122, 1270.

Kennedy, A.C., Linton, A.L. \& EAton, J.C. (1962) Urea levels in the cerebrospinal fluid after haemodialysis. Lancet, i, 410.

Kennedy, A.C., Linton, A.L. \& Luke, R.G. (1963) EEG changes during haemodialysis. Lancet, i, 408.

Macnamara, M. (1967) Psychosocial problems in a renal unit. British Journal of Psychiatric Social Work, 113, 1231.

MAHer, J.F., Freeman, R.B. \& Schreiner, G.E. (1965) Haemodialysis for CRF. II. Biochemical and clinical aspects. Annals of Internal Medicine, 62, 535.

MERRILL, J.P. (1965) The Treatment of Renal Failure. Heinemann, London.

MielezareK, J. (1962) Methyldopa and depression. British Medical Journal, 2, 1471.

SCHREINER, G.E. (1959) Mental and personality changes in the uremic syndrome. Medical Annals of the District of Columbia, 28, 316.

Scribner, B.H., Buri, R., Caner, J.E.Z., Hegstrom, R. \&
BURNell, J.M. (1960) The treatment of chronic uremia by means of intermittent haemodialysis: a preliminary report. Transactions of the American Society for Artificial Internal Organs, 6, 114.

Shambaugh, P.W., Hampers, C.L., Bailey, G.L., Snyder, D. \& MerRILL, J.P. (1965) Haemodialysis in the home: emotional impact on the spouse. Transactions. American Society for Artificial Internal Organs, 13, 41.

Shea, E.J., Bagden, D.F., Freeman, J. \& Schreiner, G.E. (1965) Haemodialysis for CRF: Il. Biochemical and clinical aspects. Annals of Internal Medicine, 62, 535.

SMIRK, H. (1963) Hypotensive action of methyldopa. British Medical Journal, 1, 146.

Stenback, A. \& HaApanen, E. (1967) Azotemia and psychosis. Acta psychiatrica et neurologica Scandinavica, 43, 197.

TYLER, R. (1965) Neurological complications of acute and chronic renal failure. In: The Treatment of Renal Failure. Heinemann, London.

Wright, R.G., SAND, P. \& Livingstone, G. (1966) Psychological stress during haemodialysis for chronic renal failure. Annals of Internal Medicine, 64, 611. 